\title{
Application of Fuzzy Logic for Personnel Selection
}

\author{
V. D. Samaila \\ Department of Computer \\ Science, \\ Adamawa State University \\ Mubi, Nigeria
}

\author{
J. M. Gumpy \\ Department of Computer \\ Science \\ Adamawa State University \\ Mubi, Nigeria
}

\author{
Manga I. \\ Department of Computer \\ Science \\ Adamawa State University \\ Mubi, Nigeria
}

\begin{abstract}
Employing the right person for the right job is very important in any organization. However, many organizations have Human Resources (HR) departments to manage this problem. Consideration of the applicant temperaments and the high rate of human subjectivity were considered in this research by developing personnel selection system using Fuzzy Simple Additive Weighted (FSAW) Method. This paper aimed at developing Fuzzy Logic Framework for Personnel selection process. A three level model are developed to handle: database, conditions required from applicants and ranking of applicants according to suitability for selection, and the consideration of individual temperament was paramount. A person with a combination of the right skills and natural tendencies or abilities is found to perform the job effectively. Finally, the research revealed that applicants with best chances can be hired thus leads to high organizational performance.
\end{abstract}

\section{Keywords}

FSAW, Fuzzy logic, Decision making, applicant selection.

\section{INTRODUCTION}

Selecting applicants with the required skills and attributes that satisfies job requirements contributes greatly to the success of any organization. Human resource management (HRM) is the process involves in identifying, evaluating, selecting, hiring, motivation, training, and developing human resource (HR) to achieve organizational set out objectives [11]. The input quality of personnel relates to personnel selection [4].

Much research has been conducted on recruitment policy adaptation due to its critical role in bringing human capital into organizations [11]. Hence, Multi Criteria Decision Making (MCDM) techniques have been adopted for handling personnel selection problems [6].

Conventional personnel selection approach uses an experimental and statistical techniques approach. After using the experimental approach, decision makers with their experience and understanding of the job specifications, select personnel for the desired job. For making a better personnel selection decisions in organizations, interviews, work sample tests, assessment centers, resumes, job knowledge tests, and personality tests in human resource management are carried out [4], while MCDM techniques are used by only a few [6].

Presently, researchers have revealed that applicant selection is a strategic decision in Human resource management (HRM) since it affects organizational performance and competitive power such as customer satisfaction, innovation, product quality, and profitability. However, decision makers have widely accepted Fuzzy logic to support them in making decisions.

Simple Additive Weighting (SAW) method is employed to select applicants by matching the vacancy requirements with applicant records so as to rank applicants according to suitability for selection. The analysis is performed by the criteria and fuzzy weighting that is more dynamic, based on organizational requirements. The proposed method has the advantage of being easily implemented in any organization by the HR department, thus solve existing problems.

\section{FUZZY LOGIC SYSTEM}

The field of fuzzy logic was discovered by Lofti A. Zadeh in 1965 at the University of California, as a way of information processing based on linguistic variables. Fuzzy set theory is the mathematical basis of fuzzy logic. Fuzzy set theory deals with data imprecision. In a wider sense, fuzzy logic and fuzzy set theory are synonym: the theory that refers to the class of objects with unclear borders, whose membership is measured in specific degrees. Fuzzy logic operates very close to human understanding. In its essence, fuzzy logic has a number of valued logic which accepts some medium values between traditional values: yes/no, true/false, on/off. Fuzzy set theory has been successfully applied in many different areas of engineering including automatic control, pattern recognition, Design of structures, structural modeling and many more in the last decade [7]. Fuzzy set theory is very interesting because of its ability to handle imprecision which is existing in personnel selection system. The imprecision in fuzzy models is generally quite high [9].

Fuzzy Logic was adopted as a better method for sorting and managing information and has proven to be an excellent choice for so many Control system applications since it imitates human control logic. It can be built into anything from small, handheld products to large computerized process control systems. It uses an imprecise but very descriptive language to deal with input data more like a human operator. Fuzzy logic system is able to simultaneously handle numeric values and linguistic variable. Numerous examples of fuzzy and neuro fuzzy systems, capable of data-driven function approximation can be found. [10].

\section{MATERIALS AND METHOD}

The method used for this research is Fuzzy Simple Additive Weighting (FSAW) which is also known as weighted linear combination or scoring methods. this is a simple and most often used multi attribute decision technique.

In Modeling, the fuzzy system for personnel selection has four different input variables are used to evaluate applicant suitability based on the recommendation that personnel selection can be done using applicant temperament test, aptitude test, Computer Base Test (CBT), and the interview.

Applicant temperament is defined based on two linguistic variables: suitable, and unsuitable; aptitude test parameter is defined based on three linguistic variables: above average, average, and below average. Computer Base Test is defined based on three linguistic variables: above average, average, 
and below average and Interview is defined based on three parameters. Viz: confidence level, language spoken, and composure.

A new framework to help decision makers in selecting the best personnel out of the vast pool of applicants will be presented. The system, after comparing job requirements with applicant records shortlist and notify applicants to continue with aptitude test and interview after which the scores obtained by applicants are evaluated in the fuzzy engine which rank the applicants.

In this research, the following algorithm is adopted:

i. Human Resource Manager sets all requirements for the available job(s)

ii. The vacancies available in the organization will be advertised for applicants to apply

iii. The applicants apply for the job vacancy.

When match is found, applicants are short listed and notify via email and SMS.

iv. Shortlisted applicants are to write aptitude test, computer based test and temperament test.

v. Applicants are interviewed by the interview panels,

vi. Applicant scores are evaluated using Fuzzy Simple Additive Weighting (FSAW) and ranked based on suitability check.

Based on the outcome of the interview, applicants are accepted or rejected depending on the scores obtained by applicants.

A case study to illustrate the algorithm is presented.

A post of IT Manager of ICT department in a large scale organization is advertised. Based on the attributes: gender, age qualification, skill required, and work experience; applicants are shortlisted using fuzzy relational database.

As shown in Table 1, table 2, table 3, and table 4. Three applicants; Ali $\left(\mathrm{A}_{1}\right)$, Favour $\left(\mathrm{A}_{2}\right)$, and Vahyalla $\left(\mathrm{A}_{3}\right)$ are shortlisted to write three tests: temperament test, Aptitude test, and Computer Base Test (CBT). The general scores obtained by respective applicants are presented in table 5. Applicants are interviewed mainly on three parameters: confidence level, exposure, and composure. The Fuzzy weight $\left(\mathrm{W}_{1}\right)$ of 0.2 out which a maximum point of 1 is allocated to education where the fuzzy scores in $\mathrm{W}_{11}, \mathrm{~W}_{12}$, and $\mathrm{W}_{13}$ sum up to the total weight of $\left(\mathrm{W}_{1}\right)$. The Fuzzy weight $\left(\mathrm{W}_{2}\right)$ of 0.1 out the maximum point of 1 is assigned to work experience where the fuzzy scores $\mathrm{W}_{21}$, and $\mathrm{W}_{22}$, sum up to the total fuzzy weight of $\left(\mathrm{W}_{2}\right)$. The Fuzzy weight $\left(\mathrm{W}_{3}\right)$ of 0.1 out a maximum point of 1 is allocated to gender where the fuzzy scores $W_{31}$, and $\mathrm{W}_{32}$, sum up to the total weight of $\mathrm{W}_{3}$. And the Fuzzy weight $\left(\mathrm{W}_{4}\right)$ of 0.1 out of the maximum point of 1 is allocated to age where the fuzzy score: $\mathrm{W}_{41}$, and $\mathrm{W}_{42}$ adds up to the total weight of $\left(\mathrm{W}_{4}\right)$. Fuzzy weights are also allocated to the three written test: temperament test $\left(\mathrm{W}_{5}\right), \mathrm{CBT}\left(\mathrm{W}_{6}\right)$, aptitude test $\left(\mathrm{W}_{7}\right)$, and the interview $\left(\mathrm{W}_{8}\right)$

The fuzzy weights MEET each attribute which is a variable that could be altered at any time depending on the given priority. The attribute during a specific job selection is as depicted in table1.The next step involves the evaluation of fuzzy points obtained by applicants which finally ranked applicants as shown in table 7 .

Table. 1: General Structure for scoring candidates

\begin{tabular}{|l|l|l|l|}
\hline Attributes & Options & $\begin{array}{l}\text { Fuzzy } \\
\text { weights }\end{array}$ & Fuzzy scores \\
\hline Education & $\begin{array}{l}\text { MSc Computer } \\
\text { Science/ MSc. } \\
\text { ICT } \\
\text { BSc/Btech. } \\
\text { Computer } \\
\text { Science } \\
\text { BSc/Btech ICT }\end{array}$ & $\mathrm{W}_{1}(0.2)$ & $\mathrm{W}_{12}-0.04$ \\
\hline $\begin{array}{l}\text { Work } \\
\text { experience }\end{array}$ & $\begin{array}{l}2 \text { to 5yrs } \\
\text { Above } 5 \mathrm{yrs}\end{array}$ & $\mathrm{W}_{2}(0.1)$ & $\mathrm{W}_{11}-0.13$ \\
\hline Gender & Male & $\mathrm{W}_{13}-0.03$ \\
\hline Age & 25 to 30yrs & $\mathrm{W}_{3}(0.1)$ & $\mathrm{W}_{32}-0.06$ \\
\hline
\end{tabular}

The suitable temperament for the job placement is setup by the HR department and assigned fuzzy weight during the initial process of the selection. The system grouped all the attributes into four temperaments namely: melancholy, choleric, sanguine, and phlegmatic. When the applicant writes the temperament test, several words are populated for the applicant to choose the words that best describes his/her human tendencies. The four temperament groups have five (5) keywords each describing a temperament, thus a total of 20 keywords are randomly mixed-up within the temperament /suitability test. The applicant, choose the keywords that describe him/her, better not knowing the type of temperament he/she belongs. The system picks these keywords, compares with the kind of temperament set by the HR and the total number of keywords is assigned a fuzzy score which is then used for subsequent evaluation. For example, if the HR set the temperament suitability level to Melancholy and the applicant checks only four (4) keywords out of the total number of keywords assigned for melancholy and four (4) keywords out of the number of keywords assigned for sanguine, then the system will automatically consider the applicant as showing the characteristics of a sanguine based on the weights assigned to each of the keywords in each specified column.

The suitability of a candidate is determined based on fuzzy scores as shown in table.3.The appropriate temperament for the job placement is determined by the HR department and assigned during the initial process of the selection.

Table 2: Temperament suitability test

\begin{tabular}{|l|l|l|}
\hline Attributes & Fuzzy weight & Fuzzy score \\
\hline Suitable & & $\mathrm{W}_{61-0.07}$ \\
Unsuitable & $\mathrm{W}_{6}(0.2)$ & $\mathrm{W}_{62}-0.03$ \\
\hline
\end{tabular}


The appropriate temperament for the job placement is determined by the HR and assigned during the initial process of the personnel selection. The system classifies all the attributes into four temperamental groups namely; melancholy, choleric, sanguine, and phlegmatic.

The fuzzy weights cater for each category of temperament test which is dynamic and could be changed depending on the priority placed on Computer Skill test during a specific job search.

The CBT is based on the fuzzy scores of the attributes a total of 60 points are allocated for the test. The marks obtained by the applicants within the specified range are assigned the fuzzy score within that category. A fuzzy weight of $\mathrm{W}_{5}(0.15)$ out the maximum fuzzy point of 1 the weights: $\mathrm{W}_{51}, \mathrm{~W}_{52}$, and $\mathrm{W}_{53}$ sum up to the total weight of $\mathrm{W}_{5}(\mathrm{CBT})$. These weights cater for each category of Computer Skill test which is dynamic and could be changed depending on the priority placed on Computer Skill test during a specific job search.

Table 3: Computer Based Test

\begin{tabular}{|l|l|l|l|}
\hline Attributes & $\begin{array}{l}\text { Average } \\
\text { range }\end{array}$ & $\begin{array}{l}\text { Fuzzy } \\
\text { weight }\end{array}$ & Fuzzy score \\
\hline Above average & $45-60$ & & $\mathrm{~W}_{51-0.07}$ \\
Average & $34-44$ & $\mathrm{~W}_{5}(0.15)$ & $\mathrm{W}_{52-0.05}$ \\
Below average & Below 34 & & $\mathrm{~W}_{53-0.03}$ \\
\hline
\end{tabular}

A total of 60 points are allocated for this test. The marks obtained by the applicants within the range specified are assigned the fuzzy score within that category. A fuzzy weight of $\mathrm{W}_{7}(0.15)$ out the maximum fuzzy point of 1 the weights: $\mathrm{W}_{71}, \mathrm{~W}_{72}$, and $\mathrm{W}_{73}$ sum up to the total weight of $\mathrm{W}_{7}$ (aptitude test). These weights cater for each category of Computer Skill test which is dynamic and could be changed depending on the priority placed on Computer Skill test during a specific job search.

\section{Table 4: Aptitude Test}

\begin{tabular}{|l|l|l|l|}
\hline Attributes & $\begin{array}{l}\text { Average } \\
\text { range }\end{array}$ & $\begin{array}{l}\text { Fuzzy } \\
\text { weight }\end{array}$ & Fuzzy score \\
\hline Above average & $45-60$ & & $\mathrm{~W}_{71-0.07}$ \\
Average & $34-44$ & $\mathrm{~W}_{7}(0.15)$ & $\mathrm{W}_{72}-0.05$ \\
Below average & Below 34 & & $\mathrm{W}_{73}-0.03$ \\
\hline
\end{tabular}

\subsection{Calculations and Applicants Ranking}

Based on the attributes such as gender, age qualification, skill required, and work experience, the example below is used to demonstrate how the algorithm works.

Job title: Network Administrator and Age: between 25 and 40

Education: Minimum of Bachelor's degree or higher with CCNA certification preferably

Work experience: over 2 years

\section{Sex: Either Male or Female}

Skills required: marketing, Adapting, team type, innovator, influence, and expressive.

Based on the attributes above the HR manager sets the specific requirement which meets the job specification. High fuzzy scores are assigned to the under listed for the purposes of selecting applicants who meet the criteria described below.

Qualification: MSc. Computer Science/ MSc. ICT

Age: between 25 and 35

Work experience: between 3 to 4 years

Gender: Male

Temperament: Sanguine

Table 5: Fuzzy evaluation

\begin{tabular}{|l|l|l|ll|}
\hline Attributes & Options & $\begin{array}{l}\text { Fuzzy } \\
\text { weights }\end{array}$ & $\begin{array}{l}\text { Fuzzy } \\
\text { scores }\end{array}$ \\
\hline Education & $\begin{array}{l}\text { MSc Computer } \\
\text { Science/ MSc. ICT }\end{array}$ & & $\mathrm{W}_{11}$ & - \\
& BSc/Btech. & & 0.13 \\
& Computer Science/ & $\mathrm{W}_{1}(0.2)$ & $\mathrm{W}_{12}$ & 0.04 \\
& BSc/Btech ICT & & $\mathrm{W}_{13}$ \\
& & & 0.03 \\
\hline Work & 2 to 5yrs & & $\mathrm{W}_{21}(0.2)$ & 0.07 \\
experience & Above 5yrs & & $\mathrm{W}_{22}$ \\
& & & 0.13 \\
& & & $\mathrm{~W}_{31}$ \\
& Male & & 0.04 \\
\hline Gender & Female & & $\mathrm{W}_{32}$ \\
& & & 0.06 \\
\hline Age & 25 to 30yrs & & $\mathrm{W}_{41}(0.1)$ & 0.06 \\
& 31 to 40yrs & & $\mathrm{W}_{42}$ \\
& & & 0.04 \\
\hline
\end{tabular}

The HR manager allocates fuzzy weights and fuzzy scores on all applicants attributes based on the job requirements. The HR manager places higher values on the attributes he finds most appropriate for the job requisition. A total of 60 points are allocated for this test. A fuzzy weight of $\mathrm{W}_{7}(0.15)$ out the maximum fuzzy point of 1.0 is allocated. Each of the weights in $\left(\mathrm{W}_{71}, \mathrm{~W}_{72}, \mathrm{~W}_{73}\right)$ sum up to the total weight of $\mathrm{W}_{7}$ (Computer Skill test). These weights could be changed depending on the priority placed on Computer Skill test during a specific job search.

Table 6: Aptitude Test

\begin{tabular}{|l|l|l|l|}
\hline Category & $\begin{array}{l}\text { Average } \\
\text { range }\end{array}$ & $\begin{array}{l}\text { Fuzzy } \\
\text { weight }\end{array}$ & $\begin{array}{l}\text { Fuzzy } \\
\text { score }\end{array}$ \\
\hline Above average & $45-60$ & & $\mathrm{~W}_{71-0.07}$ \\
Average & $34-44$ & $\mathrm{~W}_{7}(0.15)$ & $\mathrm{W}_{72-0.05}$ \\
Below average & Below 34 & & $\mathrm{~W}_{73}-0.03$ \\
\hline
\end{tabular}


A total of 60 points are allocated for this test. The marks obtained by the applicants within the range specified are assigned the fuzzy score within that attributes as shown in table 6 .

Table 7: Computer Based Test (CBT)

\begin{tabular}{|l|l|l|l|}
\hline Attributes & $\begin{array}{l}\text { Average } \\
\text { range }\end{array}$ & $\begin{array}{l}\text { Fuzzy } \\
\text { weight }\end{array}$ & Fuzzy score \\
\hline $\begin{array}{l}\text { Above } \\
\text { average }\end{array}$ & $45-60$ & & $\mathrm{~W}_{71-0.07}$ \\
Average & $34-44$ & $\mathrm{~W}_{7}(0.15)$ & $\mathrm{W}_{72-0.05}$ \\
Below average & Below 34 & & $\mathrm{W}_{73-0.03}$ \\
\hline
\end{tabular}

Interview is conducted on each applicant from whom attributes are classified into: exposure, confidence level, and language spoken.

Interview is conducted on each applicant from whom attributes are classified into: exposure, confidence level, and language spoken.

Table 8: Interview score

\begin{tabular}{|l|c|l|}
\hline Attributes & Fuzzy weight & Fuzzy score \\
\hline Exposure level: & & $\mathrm{W}_{81-} 0.017$ \\
Low & & $\mathrm{W}_{82-} 0.013$ \\
Confidence level: & $\mathrm{W}_{8}(0.1)$ & $\mathrm{W}_{83-} 0.017$ \\
High & & $\mathrm{W}_{84-} 0.013$ \\
Low & & \\
Language spoken: & & $\mathrm{W}_{85-} 0.03$ \\
English and French & & $\mathrm{W}_{86-} 0.01$ \\
English only & & \\
\hline
\end{tabular}

The aptitude test is based on the fuzzy scores of the attributes as shown in table 3.4. A total of 60 points are allocated for this test. A fuzzy weight of $\mathrm{W}_{7}(0.15)$ out the maximum fuzzy point of 1.0 is allocated. Each of the weights in $\left(\mathrm{W}_{71}, \mathrm{~W}_{72}\right.$, $\mathrm{W}_{73}$ ) sum up to the total weight of $\mathrm{W}_{7}$ (Computer Skill test). These weights could be changed depending on the priority placed on Computer Skill test during a specific job search.

\subsection{Evaluations}

From the information provided in the table 4.1, the score obtained by each candidate is calculated as follows using the formula below. The fuzzy weights are multiplied with the fuzzy score assigned by the

$\sum^{n}=($ general ponit $*$ range point $)$

Applicant $\left(\mathrm{A}_{1}\right)$ grades

$=(0.2 \times 0.03)+(0.1 \times 0.04)+(0.1 \times 0.04)+(0.15 \times 0.05)+$ $(0.15 \times 0.05)+(0.1 \times 0.04)+(0.2 \times 0.03)$

$=0.006+0.004+0.004+0.0075+0.0075+0.004+0.003+$ 0.006

$=0.042$

Applicant $\left(\mathrm{A}_{2}\right)$ grades

$=(0.2 \times 0.04)+(0.1 \times 0.04)+(0.1 \times 0.04)+(0.15 \times 0.03)+$ $(0.15 \times 0.03)+(0.1 \times 0.04)+(0.2 \times 0.07)$

$=0.008+0.004+0.004+0.0045+0.0045+0.004+0.014$

$=0.043$

Applicant $\left(\mathrm{A}_{3}\right)$ grades

$=(0.2 \times 0.13)+(0.1 \times 0.06)+(0.1 \times 0.06)+(0.15 \times 0.07)+$ $(0.15 \times 0.07)+(0.1 \times 0.06)+(0.2 \times 0.07)$

$=0.026+0.006+0.006+0.0105+0.0105+0.006+0.014$

$=0.073$

\section{RESULT}

The fuzzy system having collated all required information, the outcome of the processes yielded Table 9 where three applicants are short listed Ali $\left(\mathrm{A}_{1}\right)$, Favour $\left(\mathrm{A}_{2}\right)$, and Ussa $\left(\mathrm{A}_{3}\right)$. The applicant fuzzy scores and attributes are displayed in table 9.

Table 9: personnel information

\begin{tabular}{|l|l|l|c|c|c|c|c|}
\hline Applicant & Education & $\begin{array}{l}\text { Work } \\
\text { experience }\end{array}$ & Gender & Age & $\begin{array}{l}\text { Computer Based } \\
\text { Test (CBT) }\end{array}$ & $\begin{array}{l}\text { Aptitude } \\
\text { test }\end{array}$ & Temperament test \\
\hline Ali $\quad\left(\mathrm{A}_{1}\right)$ & $\begin{array}{l}\text { BSc/Btech.Co } \\
\text { mputer Science }\end{array}$ & 3 & $\mathrm{M}$ & 42 & 45 & 43 & $\begin{array}{l}\text { Melancholy(un } \\
\text { suitable) }\end{array}$ \\
Favour $\left(\mathrm{A}_{2}\right)$ & $\begin{array}{l}\text { BSc,/Btech. } \\
\text { ICT }\end{array}$ & 5 & $\mathrm{M}$ & 35 & 40 & 34 & Sanguine (suitable) \\
Ussa $\quad\left(\mathrm{A}_{3}\right)$ & $\begin{array}{l}\text { MSc. } \\
\text { Computer } \\
\text { Science }\end{array}$ & 6 & F & 26 & 48 & 54 & Sanguine (suitable) \\
\hline
\end{tabular}


Table 4. Depicts individual applicant score. From the table 4., if the vacancy available is only for only three people, then it's obvious that applicant $A_{1}, A_{2}$, and $A_{3}$ should be selected based on the ranks obtained. With regard to applicant $A_{3}$ whose required skill is melancholy which is different from the required skill choleric, decision makers need to explain why there is a need to choose $A_{3}$ over applicant $A_{2}$ who is a choleric. Following the decision maker's argument a choleric activity level is almost similar to melancholy since both have the same drive to work. This means that though applicant $\mathrm{A}_{3}$ is melancholic he would be chosen for placement. Here we realize that their main difference is related to their emotions. This research work focused mainly on the evaluation of the results based on the Fuzzy Simple Additive Weighted method (FSAW). Final results are communicated to the applicant either accepted or rejected.

\subsection{Selection of Candidates}

The final score obtained by each applicant is shown in the table 10. If the Available gap is for only two people to occupy, it is clear that Applicant $\mathrm{A}_{1}$, and Applicant $\mathrm{A}_{2}$ should be placed based on the ranks obtained. The research work focused mainly on the evaluation of the results based on the Fuzzy Simple Additive Weighted method (FSAW).

Table 10: applicant ranking

\begin{tabular}{|l|l|l|}
\hline Applicants & Score & Ranking \\
\hline $\mathrm{A}_{1}$ & 0.093 & 3 \\
$\mathrm{~A}_{2}$ & 0.116 & 2 \\
$\mathrm{~A}_{3}$ & 0.146 & 1 \\
\hline
\end{tabular}

\section{CONCLUSIONS}

Although, personnel selection problem has been in existence for a very long time, it has still attracted the attention of many researchers. The accuracy of the results of traditional methods such as interviews or applicants test is highly questionable. However, some researchers have focused on the application of Techniques for Order Preference by Similarity to an Ideal Solution (TOPSIS), Fuzzy Elimination Et Choix Transduisant la REaite (ELECTREC), Fuzzy Analytical Hierarchy Process (AHP), Preference Ranking Organization Method for Enrichment Evaluation (PROMETHE), and SAW methods, expert systems, to deal with personnel selection problem.

Fuzzy Simple Additive Method (FSAW) can be applied to solve the issues faced by decision makers in personnel selection. The method will applied on data obtained from applicants. Much emphasis is placed in this research to minimize vagueness, subjective value judgment and imprecision. These factors affect personnel selection in most organizations. A new method has been presented for evaluating the overall suitability of job applicants, using the weights allocate to skills and attributes in advance of personnel evaluation, the fuzzy method achieves a rational basis for assessment. However, It is recommended that an individual's medical examination (medical tests that are conducted to ensure physical fitness of the potential employee/applicant be factored and a fuzzy number assigned to influence applicants chance of obtaining the job. This will greatly decrease chances of employee not coming to work regularly which will affect organizational performances. To further minimizes human subjectivity the system could be developed with the ability of online test, after shortlist applicants could be interviewed and successful applicants are notified email and SMS

\section{ACKNOWLEDGMENTS}

We acknowledge all the authors cited for their contributions in the field.

\section{REFERENCES}

[1] Aitchinson, M. 2006. E-recruitment best practice in the private sector. A research project.

[2] Bowman, M., Debray, S. K., and Peterson, L. L. 1993. Reasoning about naming systems.

[3] Bedi S, R., Malani, O., and Dwi., N. 2016. Design of Information System.

[4] Chien, C. F., and Chen, L. F. 2008. Data mining to improve personnel selection and enhance human capital: A case study in high-technology industry. Expert Systems with Applications, 280-290.

[5] Daramola, J.O., Oladipupo, O.O., and Musa, A.G. 2010. A fuzzy expert system (FES) tool for online personnel recruitments. An International Journal Information System..99920003.

[6] Dursun, M., \& Karsak, E. E. 2010. A fuzzy MCDM approach for personnel selection. Expert Systems with Applications, 37(6), 4324-4330.

[7] Galanaki, E. 2002. The decision to recruit online. A descriptive study career development

[8] Maura, B., Denis, S. Silveira, \& Eliane, M. 2003. The e-recruiting tool based on fuzzy logic. Conference paper

[9] Misha, L., Sonja, P. L., and Bruce, B. 1999. Fuzzy approach to personnel Selection. Working Paper 44/99.

[10] Regina, H., 2012. The fuzzy logic approach to personnel selection and placement. A Thesis submitted to the Department of Computer Science.

[11] Safari, S.M., Vazin, K., \& Ali K, 2014. Identifying and ranking the Human Resources Management Criteria influencing on organizational performance using MADM Fuzzy techniques, Management Science Letters, 4, $1577-1590$ 